\title{
EDITORIAL
}

\section{Teaching Law for Forensic Medical and Forensic Science Students}

\author{
Induwara Gooneratne
}

The term "forensic" is related to law or court functions. In forensic medicine or in forensic sciences, a practitioner would assist court in conducting relevant investigations and providing facts and evidence based opinions to solve legal issues. The contributions by experts in forensic medicine and science to solve legal issues in court room have been immense and of paramount importance.

As forensic medical and science practitioners in their everyday activities deal with law enforcement officers or court officers and engage in legal procedures, a question arises as to whether or not these forensic practitioners should know the law and legal concepts relevant to their practice and if so, should forensic medical and forensic curricula cover the law and legal concepts adequately by a trained legal expert. Then the extent to which these concepts should be covered and what concepts to be covered need to be discussed.

There are two main positions on this situation. On the one hand some believe that the practitioners of forensic medicine and sciences should be aware of the law and legal concepts that are relevant to them so that they would be in a better position to provide a relevant opinion or a report to court to suit the needs for the court. However on the other hand, some believe that the law and legal concepts are for the lawyers and judges and that the responsibility of the forensic medical and science practitioner is to provide a truthful, unbiased report to court and answer any question that may be raised in the process. This fraction further believes that the imparting of these law and legal concepts to forensic practitioners can skew the opinions they provide and tend to 'lawyer' their opinion which may adversely affect the fairness and administration of justice.

My research in to this issue especially the focus group discussions I had with medical students, law students and informal discussions with practitioners revealed that it is important to formally impart essential and relevant legal concepts to practice forensic medicine and science so that the forensic practitioners will be able to provide their report and their evidence more meaningfully. Out of the legal concepts that were thought to be useful and relevant were mostly concepts from criminal law and law of evidence. The concepts included but not limited to " what is a crime, elements of crimes, legal and factual causation, law of murder and homicide, law of hurt, sexual offenses, child abuse, negligence, legal process of crime investigations, expert evidence, law related to death and death investigation'. Further I strongly believe that elements of proof and approaches to proof of evidence too are highly relevant to forensic practitioners. However it will not be possible to impart all these in an under 
graduate curriculum but it is possible to provide the required knowledge of law to post graduate forensic students as part of their core curriculum or optional curriculum. It must be noted that it has been observed by the author that nonlawyers or medical practitioners tend to teach and sometimes write articles on content legal issues which may not be the right approach where it is always possible to hire a trained legal academic or legal practitioner for this purpose.

On the other hand it is also important to consider the opposing argument which posits that 'the object and purpose of a forensic practitioner or an expert witness to court is not to have another lawyer in court but to have an expert who will provide a comprehensive report and answer raised questions in an unbiased manner in examination in chief and in cross examination so that the legal experts will isolate and use the pieces of evidence they want to establish their pan ultimate and ultimate probanda to suit the needs of the court.

It has also been observed by the author that some expert witnesses tend to provide evidence as if they were 'eye witnesses' to the event in question which is detrimental to the fairness, scientific scrutiny, due process and administration of justice which can be overcome by educating the forensic practitioners on the law of evidence.

In conclusion, the position of the author is that it is relevant and essential that the forensic practitioners are imparted with relevant and important legal concepts at least superficially by a trained legal academic/lawyer but striking a balance between the possibility of their presentation of facts and opinions could be skewed on the one hand o VS the forensic practitioner provides an unbiased opinion to court meaningfully having an idea as to what they should provide why and how. 